IJLRES - International Journal on Language, Research and Education Studies

ISSN: 2580-6777 (p); 2580-6785 (e)

DOI: $10.30575 / 2017 /$ IJLRES-2018050807

Vol. 2, No. 2, 2018

Page: $228-236$

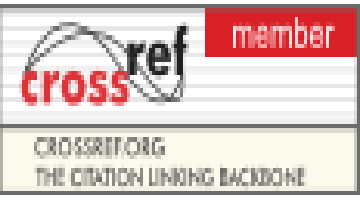

\title{
THE EVALUATION OF NATIONAL CADRE TRAINING PROGRAM (PKN) OF CENTRAL BOARD OF INDONESIAN MOSLEM STUDENT MOVEMENT (Evaluation Study of Kirkpatrick Model)
}

\author{
Ahmad Riduan \\ School of Postgraduate, State University of Jakarta, Indonesia \\ sahabatriduan@gmail.com
}

\begin{abstract}
This study aims to evaluate the implementation of the Training of national the members. This research was conducted in PB PMII. The methodology used is the evaluative research through the Kirkpatrick model includes four levels, namely; reaction, learning, behavior and result. The results showed that: (1) participants are satisfied with the service of the Committee in terms of infrastructure, material/curriculum, instructors, and schedule, (2) the participants mastered the training material which can be seen from the test results given the active as well as provide questions, attend any activity, (3) any change of behavior for participants after returning to their respective regions as well as pedagogic competencies, personality, social, and professional, and (4) productivity increase with the presence of the module, the method of organization development and problem solving as well as improved performance through public speaking ability discipline, liveliness, new ideas, and ethics to NU. Based on the findings, it was concluded that this aspect of the reaction, learning, behavior and the result is already very good.
\end{abstract}

Keywords: Evaluation, Programs, Training, Cadre, National

\section{INTRODUCTION}

This National Cadre Training Program was made on the basis of anxiety all the PMII alumni about the notion of organizational ideals collectively, ranging from new cadres to alumni who have been full kaderisasi who become stakeholders in every leadership. Training is defined as a systematic process aimed at assisting participants in improving their knowledge and skills, and developing positive behaviors. Through the learning experience that has been followed is expected to help participants achieve better performance.

Training is very important to do in an organization to increase loyalty and cadre performance to achieve organizational goals. In the process of regeneration of cadres, PKN batch 1 and 2 was devoted to the National Executive Board of the Indonesian 
Moslem Student Movement. Next, the batch 3, 4 and 5 were commenced for the leaders of the board of Province Executives and District leaders throughout Indonesia. At least the training alumni of this National Cadre Training has amounted to 200 people all over Indonesia..

Based on the reality above, it is considered important to evaluate this regeneration program, in accordance with predetermined objectives and prerequisite conditions set by the organizer. So the authors assumed that it is necessary to conduct research under the title "THE EVALUATION OF NATIONAL CADRE TRAINING PROGRAM (PKN) OF CENTRAL BOARD OF INDONESIAN MOESLEM STUDENT MOVEMENT (Evaluation Study of Kirkpatrick Model)"

\section{LITERATURE REVIEW}

\section{Basic Concept of Evaluation Program}

Evaluation is a systematic, planned and achievement of objectives, involving the collection of data relating to organizations and programs. Evaluation is a process or activity of selection, collection, analysis and presentation of information that can be used as a basis for decision making and subsequent programming ${ }^{1}$. Thomas G. Cimmings and Christopher G. Worley describe the evaluation with the following definition, "Evaluation is concerned with Providing feedback to practitioners and organization members about the progress and impact of interventions" 2 .

In further discussion in accordance with this article is explained about the evaluation of the program. Of the many definitions that still distinguish the evaluation and evaluation of the program itself. Although it comes out of a language family and a similar target for judgment and decision making. According to Goodie, many useful program evaluations are conducted at the implementation, outcome and cost and cost efficiency levels ${ }^{3}$.

${ }^{1}$ Jan Neumann, Andrew Robson, Diane Sloan. 2017. Monitoring And Evaluation Of Strategic Change Programme Implementation. International Journal Evaluation and Program Planning. P. 3

${ }^{2}$ Thomas G Cimmings, Christopher G. Worley. 2015. Organization Development $\mathcal{E}$ Change 10 Editions. USA: Cengange Learning. P. 207

${ }^{3}$ Sarah Goodier, et. al. 2017. The Need For Theory Evaluation In Global Citizenship Programmes: The Case Of The Gcsa Program5me. Evaluation and Program Planning. P. 5 


\section{The Effect of Self-Concept on the Mathematics Learning Achievement DOI: 10.30575/2017/IJLRES-2018050806}

Program evaluation is a systematic collection of information on activities, characteristics, and outcomes to make decisions about programs such as continuing programs or improving programs in the future. This is in the opinion of Carpenter who said that in the evaluation of unit operations and programs, the unit collects, analyzes, and uses a broad array of information and data from course evaluations ${ }^{4}$.

Based on the above explanation, it can be concluded that the evaluation program is a series of activities undertaken to see the success of a program, where the success of the program can be seen from the achievement of the objectives of the program implementation. If it has been achieved, how is the quality of the achievement of the activity, and if it has not achieved what caused, is there any other factors that cause the program to be unsuccessful. In short, program evaluation is carried out to find out the advantages and disadvantages of a program.

\section{Training}

This training is provided to create individuals or working groups through specific instructions and practices. Training may include informal, as well as formal, to transfer the knowledge and skills of the members of the organization. According to Shahrooz and Farjad that training and development is defined by Dessler as a process that utilizes various methods to provide new and existing employees with the skills they need to perform the job ${ }^{5}$. Furthermore, according to Hanaysha that training is defined as systematic process that aims to help employees to develop their knowledge and skills, and develop the positive behavior through learning experience that is expected to help employees achieve greater performance'

This is in line with Abolfazl Miri's statement that training is one of the most important parts of an organization's overall strategy. Before starting a particular venture

\footnotetext{
${ }^{4}$ Carpenter, Dale et.al. 2016. Assessment of Operational Effectiveness For Education Program Providers. Journal of Assessment and Institutional Effectiveness. P. 105

${ }^{5}$ Farjad, Shahrooz. 2012. The Evaluation Effectiveness of training courses in University by Kirkpatrick Model. Case Study: Islamshahr university, International Journal Procedia- Social and Behavioral Sciences. P. 283

${ }^{6}$ Hanaysha, Jalal. 2016. Examining the Effects of Employee Empowerment, Teamwork, and Employee Training on Organizational Commitment. International Journal Procedia - Social and Behavioral Sciences. P. 229
} 
or considering a potential acquisition, the first question arises that, whether there are skills present in the organization or not?

According to $\mathrm{Lu} \mathrm{Yi}$, training is an essential component of ensuring safe operations. Here we consider the relationship between training and organizational risk and create a conceptual model illustrating how risk decreases by training, and how a lack of training increases risk. Training is an important component in an organization to consider the risks that will occur within an organization' 8 .

\section{National Cadre Training (PKN)}

National cadre training is the leadership cadre in the organization that formulates the cadres who participate in the training can be a motivator and mentor who has a spirit of struggle with knowledge, skills and good performance. Being a national leader means that there will be many viewpoints from local leaders. So demanding that a national leader can be a good example.

Kreitner and knicki state that there are four common definitions of leadership, they are; leadership is process between a leader and followers, leadership involves social influence, leadership occurs at multiple levels in organization, leadership focus on a goal accomplishment. In other words, that the four general definitions of leadership are the processes between leaders and their followers, leaders are social influences, leadership is at several levels within the organization, and leadership focuses on achieving goals ${ }^{9}$.

In the implementation, these trainees are trained by the team of instructors with targets and goals as the following four points; 1). Develop Knowledge, 2). Enforcing Discipline, 3). Strengthening Spirituality, 4). Strengthening Physical Forging. So in the implementation of this national cadre training PMII PB as an organization that conducts training on cadres, members of course want an increase to knowledge, skills and attitudes, but the purpose of training is not only limited but also expected to develop the organization according to talent so that someone can do the job and assignment tasks as required ${ }^{10}$

\footnotetext{
${ }^{7}$ Seyyed Abolfazl Miri, et. al. 2014. Staff Organization Training: Designing, Stages, and Methods. International Journal Procedia - Social and Behavioral Sciences. P. 228

${ }^{8}$ Lu Yi, et. al. 2014. Conceptual Modeling Of Training And Organizational Risk Dynamics. International Journal Procedia Engineering. P. 313

Hill, 2007. P. 509

${ }^{10}$ PB PMII. Database PMII Se-Indonesia 2014-2016. P. 94
} 


\section{Evaluation Program of Kirkpatrick Model}

Kirkpatrick's evaluation model is motivated by the opinions of Drozdova \& A.I. Guseva said that "to evaluate the effectiveness of the initial training, can be used the integrated four-level evaluation model of Donald Kirkpatrick"11. Furthermore, according to Cynthia M. Clark, argues that "the Kirkpatrick Model of Evaluation is a useful framework for describing the evidence produced by simulation evaluation strategies"12.

In line with this, according to Richard B. Gunderman, proponents of Kirkpatrick's approach holds that, properly applied, his model can enrich education both prospectively in the planning phase and retrospectively in the evaluation phase ${ }^{13}$. Meanwhile, according to Lorraine Armstrong, the Kirkpatrick Education Evaluation Model was used to explore the impact of teaching approaches. Enabling and impeding factors were thematically analysed. A narrative synthesis of findings is presented. ${ }^{14}$

Based on the above explanation, it can be concluded that Donald Kirkpatrick's evaluation model is one of the most popular evaluation models for measuring training effectiveness. This model has 4 levels of level; level 1 (reaction) consists of facilities and infrastructure, materials/curriculum, instructor, supervision and schedule, level 2 (learning) consists of mastery of the material, and the activity of the participants, level 3 (behavior) consists of behavior change, level 4 (result) consisting of productivity and performance.

\section{METHODOLOGY}

This evaluation study uses an evaluative research model with Kirkpatrick evaluation model. This research was conducted in PB PMII Jakarta as initiator and program implementer. The time of evaluation research will be conducted on the training of national cadres of class VI (PKN VI) in Jakarta.

${ }^{11}$ A.A Drozdova,. \& A.I. Guseva. Modern technologies of e-learning and its evaluation of efficiency. International Journal Procedia - Social and Behavioral Sciences, 237, 2017. P. 1034

${ }^{12}$ Cynthia Clark M. et. al. Nursing Graduates' Ability to Address Incivility: Kirkpatrick's Level-3 Evaluation. International Journal Clinical Simulation in Nursing, 2014. P. 427

${ }^{13}$ Richard B Gunderman, Stephen Chan. Kirkpatrick's Evaluation of Educational Programs and its Relevance to Academic Radiology. International Journal Academic Radiology, 22, 2015. P. 1323

${ }^{14}$ Lorraine Armstrong, et. al, An Evaluation Of Approaches Used To Teach Quality Improvement To Preregistration Health Care Professionals: An Integrative Review, International Journal of Nursing Studies, 73, 2017, P. 70. 


\section{The Effect of Self-Concept on the Mathematics Learning Achievement \\ DOI: 10.30575/2017/IJLRES-2018050806}

The data collected in this research is done through questionnaires, interviews, document tracking, and observation. Technique Data analysis used in this evaluation research is descriptive analysis, which is by describing and interpreting data from each indicator of reaction, learning, behavior, and result aspect. Data from the results of the study were analyzed descriptively by presenting the results of descriptive statistical calculations in the form of frequency tables and percentages obtained from the results of research.

\section{FINDINGS AND DISCUSSION}

\section{Level of Reaction}

In the evaluation of reaction level consist of facilities and infrastructure, materials / curriculum, instructor, supervision and schedule so that it can be concluded that from the aspect of facilities and infrastructure, the majority of respondents give good response with percentage of $75 \%$, so that the facilities and infrastructure of National Cadre Training activities are good and can help the success of the activities despite the lack of existing infrastructure such as health service units, libraries, completeness of books, reading rooms and catalog availability. While on the material suitability aspect with the needs of learners, the majority of respondents gave good appraisal with $54 \%$ percentage so that the training materials provided were according to the needs of the participants. The material given at the time of PKN is the material about Ideology keNUan, Nationality, Student Affairs, and Politics.

Similarly to the instructor aspect, the majority of respondents provide good grades with a 55\% percentage of the instructor's ability to direct the focus on training, the ability of the instructor to make the atmosphere pleasant and not monotonous, the ability of the instructor encourages participants to ask interesting knowledge and style that motivates the spirit of the participants so that the participants are interested to be more active learning is a new knowledge that can be passed on by the trainees in the activities in place, as well as the instructor is very mastering the training materials and able to explain the material more actual so that more updates and easy to understand the trainees. In addition, the instructor is also able to answer various questions given by the trainees.

Furthermore, in the supervision aspect, the majority of respondents gave good assessment with $65 \%$ percentage of the committee's ability to supervise the participants 
in the learning, the ability of the committee in monitoring and supervision in the dormitory and the ability of the committee in the practice of worship. So that the ability of the committee in monitoring and supervision has been considered good. While on the aspect of time, respondents gave good ratings with the percentage of $55 \%$ so that in general respondents provide good assessment of the management of the time of the committee. The time allocation is divided into several parts of them; opportunity participants to respond to learning materials in training, allocation of time to rest and perform worship.

Based on the results of general evaluation related to the reaction level is categorized well and has been as expected participants.

\section{Level of Learning}

In the evaluation of learning level consisting of mastery of the material, and the activity of the participants, it can be concluded that in the academic aspect or mastery of the training materials can be seen from the test results given at the end of the training that all participants are declared passed in this PKN activity. This means that the participants are able to answer some final tests from the committee to measure the pass or absence of PKN participants.

Furthermore, in the aspect of the liveliness of the participants, it can be seen from the liveliness of the participants to ask questions, respond to questions, actively attend each activity, and have the ability to solve problems by doing some steps to solve various problems.

Based on the results of general evaluation related learning level categorized with good value.

\section{Level of Behavior}

At the behavioral level evaluation, specifically behavioral changes, respondents gave an assessment agreeing with a percentage of $4.5 \%$. This means that in general the majority of respondents agree to a change of behavior for participants after returning to their respective areas. Such behavioral changes lead to the establishment of such competencies; pedagogic competence, personality competence, social competence, and professional competence. 
Based on the results of general evaluation related to the level of behavior, then this level is categorized as having good value

\section{Level of Result}

In the evaluation of result level, this component consists of productivity and performance. From this level, it can be concluded that in the aspect of productivity has increased, it is seen by the many products produced such as modules, organizational development methods and problem solving as well as efforts to make new breakthroughs to improve the organization of PMII.

Similarly to the performance aspect, respondents gave excellent ratings with $50 \%$ percentage. This means that participants will experience improved performance after returning to their respective areas. These performance improvements include the ability of public speaking, neatness, discipline, liveliness, new ideas, and ethics to the NU.

Based on the general evaluation results related to the result level, it can be categorized as having excellent value.

\section{CONCLUSION}

Based on the research findings and discussion above, it can be concluded that (1) the participants are satisfied with the service of the committee in terms of facilities and infrastructure, materials / curriculum, instructor, supervision and schedule, (2) the participants master the training material which can be seen from the achievement of test result (3) behavior change for participants after returning to their respective areas and possessing pedagogic, personality, social, and professional competencies, and (4) increased productivity with modules, organizational development methods and problem solving and improvement of performance through the ability of public speaking discipline, liveliness, new ideas, and ethics to the NU.

\section{BIBILIOGRAPHY}

Armstrong, Lorraine, et. al. An Evaluation Of Approaches Used To Teach Quality Improvement To Preregistration Health Care Professionals: An Integrative Review. International Journal of Nursing Studies, 73, 2017.

Carpenter, Dale et.al. 2016. Assessment of Operational Effectiveness For Education Program Providers. Journal of Assessment and Institutional Effectiveness. 
Clark, Cynthia M. et. al. Nursing Graduates' Ability to Address Incivility: Kirkpatrick's Level-3 Evaluation. International Journal Clinical Simulation in Nursing, 2014.

Cimmings, Thomas G. Christopher G. Worley. 2015. Organization Development \& Change 10 Editions. USA: Cengange Learning.

Drozdova, A.A. \& A.I. Guseva. Modern technologies of e-learning and its evaluation of efficiency. International Journal Procedia - Social and Behavioral Sciences, 237, 2017.

Farjad, Shahrooz. 2012. The Evaluation Effectiveness of training courses in University by Kirkpatrick Model. Case Study: Islamshahr university, International Journal Procedia- Social and Behavioral Sciences.

Goodier, Sarah et. al. 2017. The Need For Theory Evaluation In Global Citizenship Programmes: The Case Of The Gcsa Programme. Evaluation and Program Planning.

Gunderman, Richard B. Stephen Chan. Kirkpatrick's Evaluation of Educational Programs and its Relevance to Academic Radiology. International Journal Academic Radiology, 22, 2015.

Hanaysha, Jalal. 2016. Examining the Effects of Employee Empowerment, Teamwork, and Employee Training on Organizational Commitment. International Journal Procedia - Social and Behavioral Sciences.

Krietner, Robert dan Angelo Knicki. Organizational Behavior. New York, McGrawHill, 2007.

Miri, Seyyed Abolfazl, et. al. 2014. Staff Organization Training: Designing, Stages, and Methods. International Journal Procedia - Social and Behavioral Sciences.

Moldovan, Liviu. Training Outcome Evaluation Model. International Journal Procedia Technology, 22, 2016.

Neumann, Jan, Andrew Robson, Diane Sloan. 2017. Monitoring And Evaluation Of Strategic Change Programme Implementation. International Journal Evaluation and Program Planning.

PB PMII. Database PMII Se-Indonesia 2014-2016

Yi, Lu et. al. 2014. Conceptual Modeling Of Training And Organizational Risk Dynamics. International Journal Procedia Engineering. 